\section{MATHEMATICS AT THE NATIONAL PHYSICAL LABORATORY}

$T^{H}$ HE National Physical Laboratory is proposing to extend its activities by the establishment of a Mathematics Division. It may be of interest to sketch the scope of the project as it is at present planned, though the plans may, of course, be modified in the light of growing experience.

The general aim may best be described by an extract from the report of an Interdepartmental Technical Committee recently appointed to consider the advisability of setting up such an establishment. This Committee decided that there is a strong case for an organization which would: (1) undertake research into new computing methods and machines ; (2) encourage the development of new computing methods and instruments and the dissemination of knowledge of them and of existing methods ; (3) deal with problems arising from statistical science, in particular by assisting in the application of statistical methods to research, development and production problems in industry and to problems arising in the physical sciences and engineering, and by research into new statistical techniques; it would in general exclude economic, sociological and biological statistics from its purview ; (4) advise on the need for new mathematical tables, and, if necessary, prepare them ; (5) provide computing services for Government departments and industry; (6) act as consultant on mathematical matters to Government departments and industry.

The Committee recommended that the National Physical Laboratory should undertake these duties, and with the view of doing so the Mathematics Division is being established. It is proposed at first to organize it in three sections, concerned respectively with computations using existing machines; with statistics; and with work of the differential analyser type, including the construction of new types of machines.

For the computing section there will be a full range of modern calculating machines, including the punched-card type, and very likely new machines may be developed for specialized purposes. There will be a comprehensive library of mathematical tables. Any spare time of the section will be devoted to the tabulation of functions of general utility.

The second section will be concerned with statistical methods and their use in industry. The methods of 'quality control' of production are now well established in industry, and at the practical levels can look after themselves, but there is room for much work in a general oversight of the subject, and in the further study of data provided by 'Q.C.' records. There is also much scope for the use of statistical methods in the planning of experiments in physics and engineering in the same way as is already well established through the work of Fisher and others in the biological sciences. It is not contemplated that the work of the section should extend into biology or sociology, as this would enlarge its scope out of all proportion, and would bring it into fields which are inappropriate for the National Physical Laboratory.

The third section will deal with work using what may be described as analytical engines, including the differential analyser and other machines both existing and awaiting invention. From progress already made elsewhere in such matters, it is certain that this field is capable of great developments, but it is more difficult to predict in what directions they will lie.

In setting up a Mathematics Division there is no intention of supplanting other existing activities. There are already in the Government service a number of mathematical groups fulfilling important specialized functions; for example, the Nautical Almanac Office. These will continue to work as before, but the new Division should be able to provide service for them by advising on their methods and perhaps assisting them in times of pressure. So too there will be no supersession of industrial work in mathematics, but it is intended that there shall be close co-operation. This should encourage the development inside industry of the use of mathematical methods, which recent experience has undoubtedly shown to be of the greatest value.

\section{BRITISH LIBRARY OF POLITICAL AND ECONOMIC SCIENCE}

THE annual report of the British Library of Political and Economic Science, which is housed in the London School of Economics and Political Science, for the year ended July 31,1944 , includes a retrospect of 1933-44. In this ten years the Library added 104,450 bound volumes to its shelves, and 154,368 cards to its author catalogue. During 1934-35 the Library added to its shelves 4,549 treatises and was receiving currently 3,339 periodical titles, as against 5,445 treatises and 4,506 periodicals in 1938-39, the last year of normal working. In the years immediately preceding the War, much was done to strengthen the staff and to improve its status. This larger and more highly qualified staff enabled the whole of the administration of the Library to be reorganized and the services to be greatly improved.

The survey is largely one of the work of 1934-39. Intensive efforts were made with much success to set up an international library truly representative of the social sciences. Many complete sets of important periodicals were secured, and gaps filled in existing sets. A new system of combined work-card and draft-catalogue-card was devised to eliminate wasteful routine tasks, and, in conjunction with a new arrangement of accession registers, was used to enable the Library to check its intake by country and by subject. A revision of the existing catalogue was undertaken, and after nine and a half years intensive work has at last been completed. With regard to cataloguing the uncatalogued material, all the non-official periodicals and almost all the official periodicals held by the Library have been included; 12,732 old pamphlets have also been catalogued, although many times that number still await attention, and $\mathbf{5 , 4 8 2}$ non-serial official publications have been catalogued and entered in chronological sequence under the issuing department of the relevant Government. In addition, 4,852 cards have been entered for treatises discovered to be in the Library but not in the cata. logue. The separate catalogue to the Edward Fry Library of International Law has been revised and some 5,000 duplicate entries inserted in the main catalogue.

One of the many real needs of the Library is an adequate catalogue room to hold not only the rapidly expanding catalogues, but also adjacent thereto a much larger collection of bibliographies and works of reference. The principal stacking problem has been that of space. Reviewing the improvements made in 